\title{
An Optimized Supply Chain Planning Model for Manufacture Company Based on JIT
}

\author{
Ruilin Guo \& Qi Tang \\ School of Management, Tianjin Polytechnic University, Tianjin 300387, China \\ E-mail: guorl2008@yahoo.cn
}

\begin{abstract}
With an aim to resolve the problem of the increasing costs of supply chain in Manufacture Company, an integrated supply chain management model, driven by market demand, is brought forward in this paper, based on the analysis of existing integrated models of supply chain. The management model integrates purchase, production and sale plans with logistics plans used JIT. In order to build an integrated supply chain system which contains the inside management system and the outside supply chain system of manufacturing firm and a conceptual framework of integrated supply chain planning is also designed. This paper uses a three-stage integrated supply chain planning model to make supply chain plans, and a classification evaluation model is also suggested to analyze the feasibility of planning by comparing the planned cost with the anticipated cost. Research results indicate that this three-stage integrated supply chain planning model can optimize and reduce the costs of supply chain for manufacturing firms very well.
\end{abstract}

Keywords: Integration Model, Manufacture Company, Supply Chain

\section{Introduction}

The globalization of business and the increasingly competitive pressures have driven many manufacturing firms to develop an effective supply chain planning to minimize the supply chain cost; supply chain planning is becoming the crucial element of company management. Supply chains have traditionally been fragmented, failing to integrate the business functions in logistic chain process. Many problems, such as increased inventory carrying costs, longer order lead times, and difficulty in responding proactively to real-time changes, have decreased profits and weakened customer goodwill, which can be resolved by integrating supply chain management systems for warehousing and transportation.

A supply chain may be defined as an integrated process wherein a number of various business entities (i.e., suppliers, manufactures, distributors, and retailers) work together in an effort to: acquire raw materials, convert this raw material into specified final products, and deliver these final products to retailers. The main processes in this integrated process are the production planning, control, distribution and logistics. In these processes, the production-logistics planning is one of the most important parts to support global optimization in supply chain management (SCM), and should be solved within the integrated planning structure.

In a manufacturing firm, sale, production, purchase and logistics planning are the important parts of supply chain planning and they are interactive. The production and purchase planning describes both the design of process and management of entire manufacturing process, while the sale and logistics planning determines how products are sold and delivered from the factory or warehouse to customers. Hence, how to design an integrated supply chain planning which contains sale, production, purchase and logistics planning is critical to the success of a manufacturing firm.

Given the remarkable changes in the manufacturing industry, companies have started to think how to link themselves inside a logistic chain in a way to generate more value for the customers and ultimately also for themselves.

An integrated three-stage supply chain planning model, which contains sale-logistics, production-logistics and purchase-logistics planning sub-model, is developed to support supply chain management in manufacturing firms, and an evaluation model is also designed to determine the feasibility of planning by analyzing the error of planned cost and anticipated cost in this paper.

\section{Supply Chain Planning System}

Supply chain is traditionally characterized by a forward flow of materials and a backward flow of information and often comprised of a set of geographically dispersed facilities where raw materials, intermediate products, or finished products are acquired, transformed, stored, or sold. This supply chain is often represented as a network (See Figure 1). 


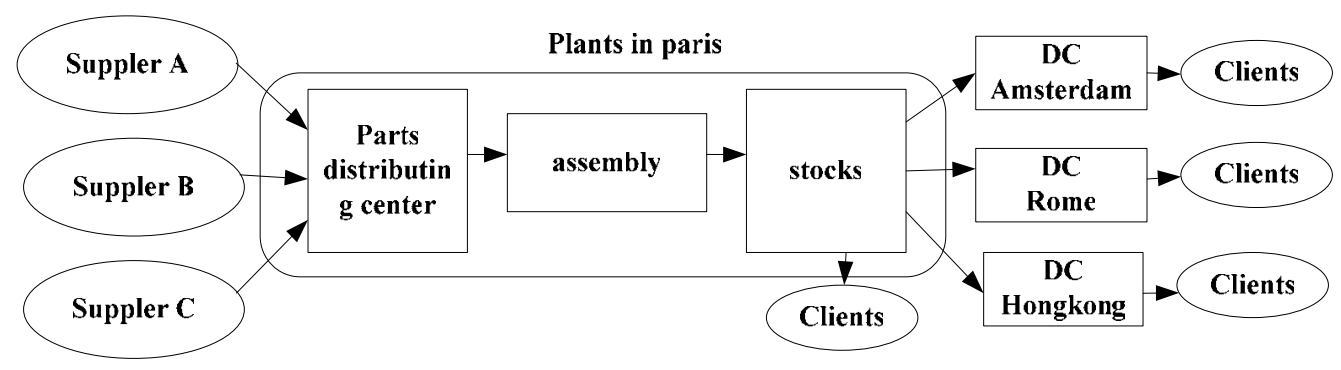

Figure 1. A simplified supply chain system

The network has four levels, products flow from suppliers to plants, the plants to distribution centers (DC), and finally DC to customers. This is a simple supply chain system based on logistics chain, and logistic value is reflected in the system. In fact, the supply chain planning system in a manufacturing firm is very complex. It needs to deal with not only the inside management system including sales, production, purchase and logistics planning, but also the outside supply chain system. The planning system analysis requires the addition of considerable details about plan-made process. An integrated supply chain planning system for manufacturing firms is designed to describe the planning process in detail in this paper (shown in Figure 2).
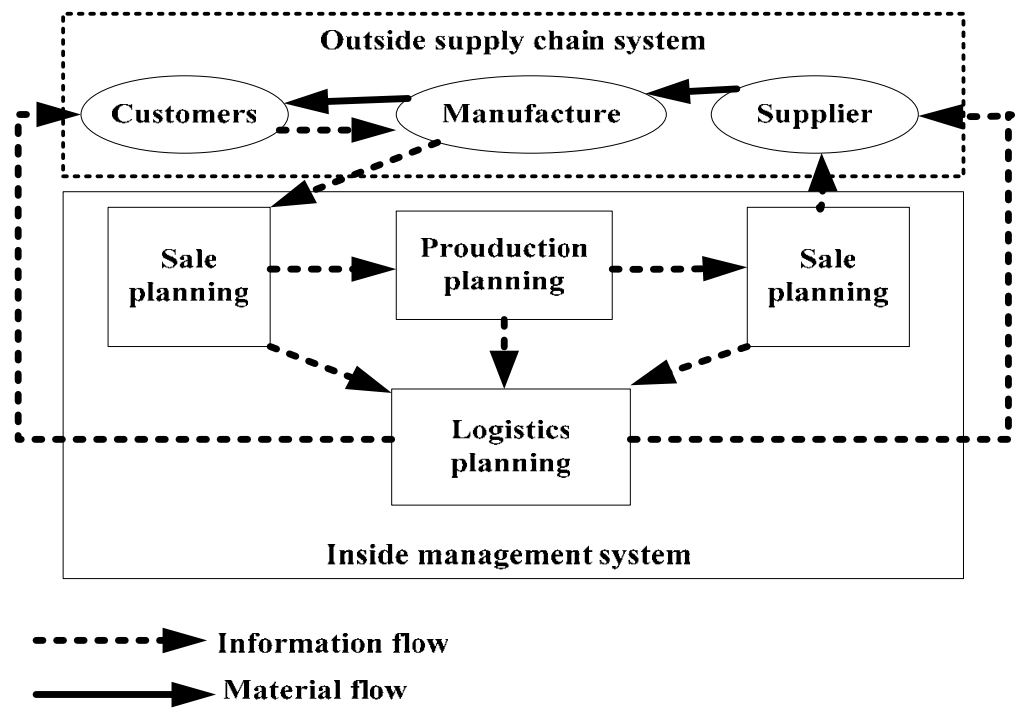

Figure 2. An optimized supply chain system

As Figure 2 suggests, this optimized supply chain planning system includes two parts: inside management system and outside supply chain system. In inside firm management system, sale, production, purchase and logistics planning are made based on market information. Market information (such as demand quantity, time, location, etc.)Gathered from customers, decides sale plans while sale plans exert influence on production plans which forms purchase plans. In this information flow process, logistics planning is integrated with sale, production and purchase planning. In the outside supply chain system, information flow starts from customer to manufacture and then to supplier, while logistics flow starts from supplier to manufacturer and then to customer. The combination of the inside management system and the outside supply chain system is finished by market information, purchasing information and logistics information.

\section{Optimized Planning Model}

\subsection{Conceptual Framework}

The integrated supply chain is the final stage in supply chain evolution and has recently been termed the "seamless supply chain". Integration is no longer constrained by organizational boundaries, and extends to both suppliers and customers. Supply chain models involve making tradeoffs between more than one business processes within the supply chain. Only the models that attempt to integrate different functions of the supply chain are regarded as supply chain models. The types of integrated supply chain models are shown in Figure 33.

The problems of conflicting goals within supply chain management process often arise in manufacturing firms', such as, the conflict between cost reduction and customers' service level Hence, supply chain management need to balance these goals and work out a feasible way to integrate purchase, sale, production and logistics into a supply chain planning 
model. A supply chain planning model which integrates purchase, sale, production and logistics is also proposed in this paper (shown in Figure 4).

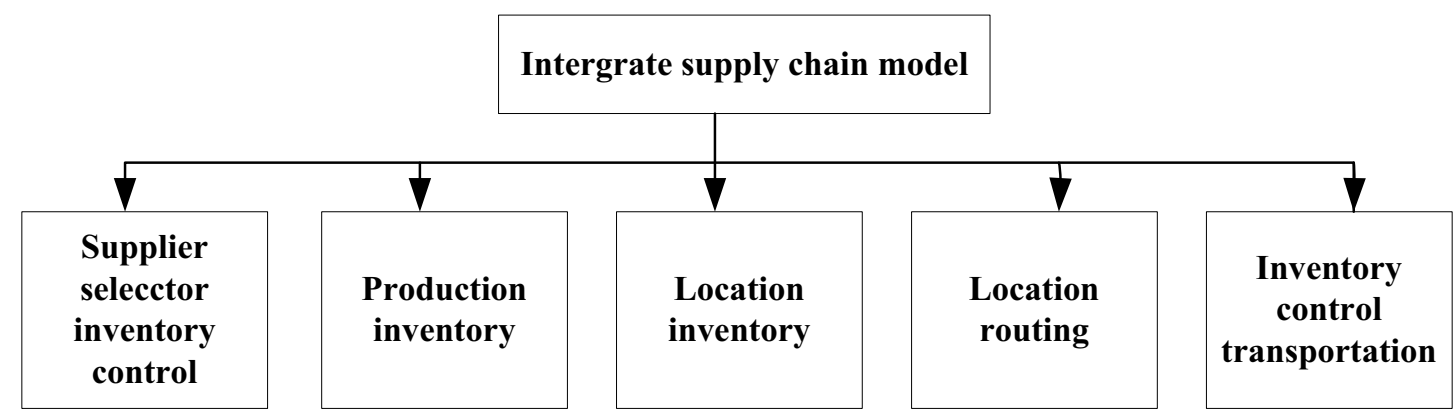

Figure 3. Types of integrated supply chain models

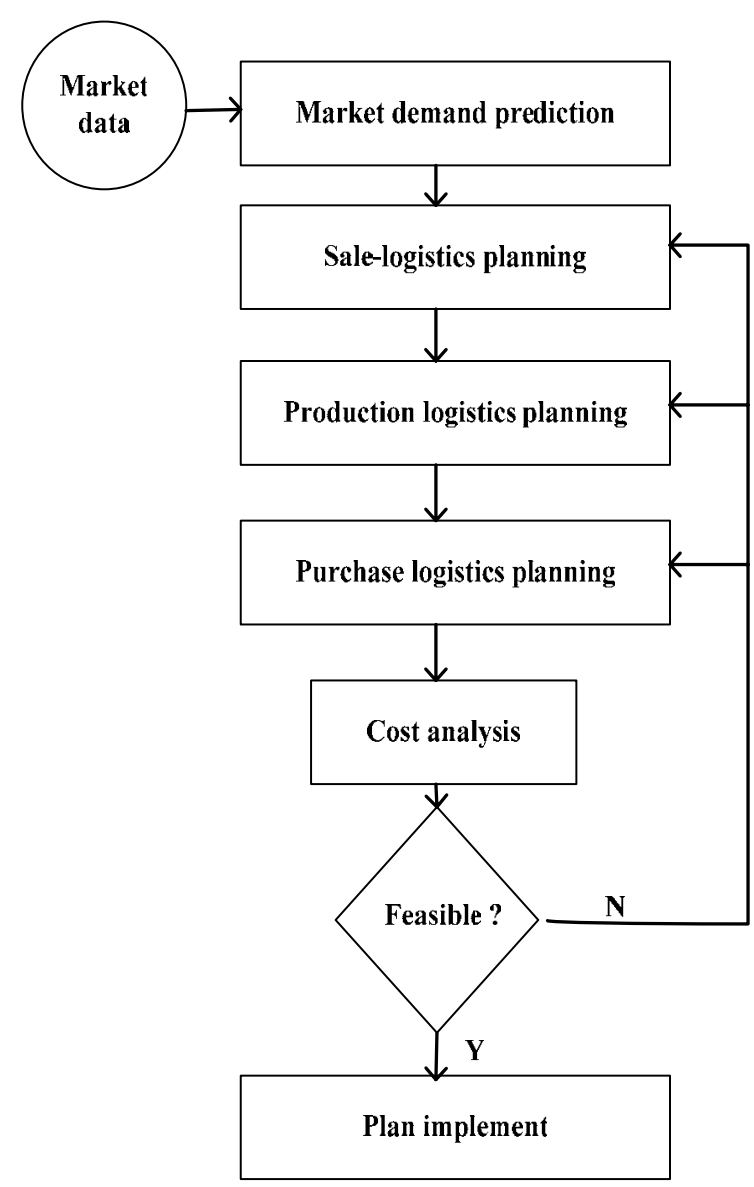

Figure 4. The integrated supply chain planning model

The proposed model consists of five main components:

1) Market demand prediction component. In this component, market data from customers, such as quantity, location, demand time and price, are applied to forecast market demand, and provide market demand information for making sale-logistics planning.

2) Sale-logistics planning component. Given the market demand information, the sale plans can be determined and the associated logistics plans should be determined simultaneously. The integration of sale and logistics planning can satisfy customers' demand well and reduce the costs of sale.

3) Production-logisticsplanning component. Theoretically production plans are made based on sale plans and production capability. However work-in-process inventory can influence production costs. Hence, the material inventory carrying costs must be considered in order to reduce order lead time and production costs, and production decisions need to take logistics plans into account. The integration of production and logistics planning can reduce the costs of production effectively. 
4) Purchase-logistics planning component. When production decisions are made, the associated purchase plans should be made simultaneously. However, purchase quantity and time exert influence on raw material inventory and transportation cost to a great extent, and the combination of purchase and logistics can reduce raw material inventory and transportation costs greatly.

5) Cost analysis component. This component is applied to evaluate the planning effects according to the comparing result of the total planning cost and the anticipated cost; the latter is determined by managers in advance based on their knowledge and experience. If the comparing result implies that the planning cost is less than the anticipated cost, then the planning is feasible, or else the planning needs to be modified.

In this integrated supply chain planning process, the sale-logistics planning sub-model, the production-logistics sub-model and purchase-logistics sub-model, are usually sequential, i.e., in turn, the sale-logistics, the production-logistics and purchase-logistics, and this sequence of steps is so called three-stage planning model.

In the continuing planning process, one of the tasks is to update these market data in time to make sure that the database for planning is complete and accurate, and then make sure that the planning methods are suitable for the type of supply chain.

\subsection{Planning model}

The planning process demonstrated within Figure 4 integrates the market demand prediction model, three-stage planning model and cost analysis model, which is presented as following:

1) Market demand prediction model

$D=f(Q, T, L)$

Hereby

\section{Market demand \\ Q Demand quantity \\ $\mathrm{T}$ Demand time \\ L Demand location}

In this presentation, market demand is the function of demand quantity, time and location derived from customers. Market demand is always changing. Therefore, the accurate, complete and timely market demand information is necessary to finish supply chain planning well.

2) Three-stage planning model

Over the past decade, the traditional purchasing and logistics functions have evolved into a broader strategic approach in terms of materials and distribution management known as supply chain management Manufacturers now have realized to use the concept of supply chain management to improve efficiency across the value chain, and logistics is the very important factor in decision- made process of sale, production and purchase. The relationship among sale, production, purchase and logistics is shown as following:

$$
\begin{aligned}
& S=f(D, L) \\
& P=f(S, L) \\
& P_{u r}=f(P, L)
\end{aligned}
$$

Hereby

$$
\begin{array}{ll}
\text { S } & \text { Sale planning } \\
\text { L } & \text { Logistics planning } \\
\mathrm{P} & \text { Production planning } \\
\mathrm{P}_{\mathrm{ur}} & \text { Purchase planning }
\end{array}
$$

In these planning models, every model (sale planning model, production planning model and purchase planning model) involves integrating with logistics planning separately. The influence of logistics planning on the total cost of supply chain of firm is reflected here. Logistics decisions exist in the total process of firm management. For example, sale process should consider the distribution network, transportation network and modes, and production and purchase process should consider ordering cost, raw material inventory and transportation cost, etc. The integration of logistics and sale, production and purchase planning completes the supply chain planning and suggests the lower cost of supply chain management in a manufacturing firm.

\section{3) Cost analysis model}

It is necessary to evaluate the total cost of supply chain when plans are made, which is called as planning cost. The 
calculation model of planning cost is shown at Equation (5). If the planning cost is very high, the planning must be modified. The planning model uses a classification evaluation model to determine the feasibility of planning by analyzing the comparing result of the planning cost and anticipated cost. The comparing model of cost and the evaluation model of planning feasibility refer to the Equation (6) and (7).

$$
\begin{aligned}
C_{s p} & =\sum_{i=1}^{m} C_{l p r}^{i}+\sum_{i=1}^{m} C_{l p u}^{i}+\sum_{i=1}^{m} C_{l s a}^{i} \\
\Delta c & =C_{s p}-C_{a}
\end{aligned}
$$

Hereby

$C_{a} \quad$ Anticipated supply chain cost

$C_{s p} \quad$ Planning supply chain cost

$C_{l p r}^{i} \quad$ Production-logistics planning cost in market i

$C_{l p u}^{i} \quad$ Purchase-logistics planning cost in market i

$C_{l s a}^{i} \quad$ Sale-logistics planning cost in market $\mathrm{i}$

$\Delta c \quad$ The error of anticipated cost and planning when

$$
\begin{cases}\Delta c \mathrm{f} 0 & \text { unfeasible } \\ \Delta c \leq 0 & \text { feasible }\end{cases}
$$

$i=1,2,3 \mathrm{~L}, m$ ( $\mathrm{m}$ the number of markets)

Firm manager adjusts this supply chain planning according to the analysis of Equation.

\section{Conclusion}

The optimized planning model is finally possible owing to advances in its information technology. The three-stage integrated supply chain planning model proposed in this paper will help manufacturing companies to understand the complex planning process of supply chain and analyze the main factors of cost- push in firm operations. The implementation of logistics as managerial concept and practices in manufacturing companies is the most important indicator for the development of logistics in the economy as whole. In the three-stage planning model, logistics planning plays an important role in reducing the cost of supply chain. The continuing process of three-stage planning ensures that the supply chain plans will respond to the market demands that are constantly changing, and the level of effort involved in the planning process will depend on the size of customers' market and the complexity of its problems.

\section{References}

Andrew P., Robert M.. (2004). The evolution towards an integrated steel supply chain: A case study from the UK. Int. J. Production Economics 89, 207-216

Beamon and B. M.. (1998). Supply chain design and analysis: models and methods. International Journal of Production Economics, 55, 281-294

Hokey Min and Gengui Zhou. (2002). Supply chain modeling: past, present and future. Computers \&Industrial Engineering, 43, 23 1-249.

Laoucine Kerbachea, James MacGregor Smith. (2004). Queueing networks and the topological design ofsupply chain systems. International Journal of Production Economics 91, 251-272

Marco Perona. (2001). The integrated management of logistic chains in the white goods industry-- A field research in Italy. Int. J Production Economics 69,227-238

Pavel Dimitrov. (2005). Logistics in Bulgarian manufacturing companies. Int. J. Production Economics 93-94,207-215

Scott J. Mason, P. Mauricio Ribera and Jennifer AFarris. (2003). Integrating the warehousing and transportation functions ofthe supply chain. Transportation Research Part E 39, 141-159.

Young Hae Lee and Sook Han Kim. (2002). Production-distribution planning in supply chain considering capacity constraints. Computers \& Industrial Engineering 43, 169-190 